\title{
Hydrothermal synthesis of yttrium and niobium co-doped anatase-type titania nanoparticles
}

\author{
Masanori HIRANO ${ }^{\dagger}$ and Shingo SATO \\ Department of Applied Chemistry, Faculty of Engineering, Aichi Institute of Technology, Yakusa, Toyota, Aichi 470-0392
}

\begin{abstract}
The metastable anatase phase of $Y_{X} \mathrm{Ti}_{1-2 X} \mathrm{Nb}_{X} \mathrm{O}_{2}(X=0-0.15)$ was formed as nanosized-particles from precursor solutions of $\mathrm{TiOSO}_{4}, \mathrm{NbCl}_{5}$, and $\mathrm{YCl}_{3}$ under mild hydrothermal conditions using the hydrolysis of urea. The aeschynite phase $\mathrm{YTiNbO}_{6}$ coexisted with anatase-type titania in the precipitate that was formed at the composition of $X=0.20$. The crystallite sizes of anatase formed under hydrothermal conditions at $240^{\circ} \mathrm{C}$ for $5 \mathrm{~h}$ were approximately $15 \mathrm{~nm}$. The diffuse reflectance spectra continuously varied and optical band gap gradually increased with increased yttrium and niobium content in the samples. The anatase formed at the composition of $\mathrm{Y}_{0.05} \mathrm{Ti}_{0.90} \mathrm{Nb}_{0.05} \mathrm{O}_{2}$ showed the same level of photocatalytic activity as that of pure $\mathrm{TiO}_{2}$. The precipitation of $\mathrm{YTiNbO}_{6}$ phase out of the anatase above $850^{\circ} \mathrm{C}$ was observed before the formation of rutile through the anataseto-rutile phase transformation. The crystallite growth of anatase in the course of heating was delayed and the phase transformation shifted into higher temperature more than $150-200^{\circ} \mathrm{C}$ via the co-presence of yttrium and niobium.
\end{abstract}

(C2011 The Ceramic Society of Japan. All rights reserved.

Key-words : Anatase, Rutile, Titania, Yttrium, Niobium, Phase stability

[Received February 21, 2011 ; Accepted April 4, 2011]

\section{Introduction}

Intensive attention has been devoted to wet chemical routes to synthesize nanometer-sized particles of inorganic materials in recent years. ${ }^{1-3)}$ The precipitation technique from aqueous solution under hydrothermal conditions, ${ }^{4)-7)}$ which is one of wet chemical routes, is attractive for the synthesis of crystalline fine ceramic particles. In general, aqueous solution routes are useful for the preparation of nanometer-sized solid solutions ${ }^{8)-10)}$ and complex-oxide particles. ${ }^{11), 12)}$

Titanium oxide (titania, $\mathrm{TiO}_{2}$ ) is a wide band gap semiconductor and has attracted attentions as photocatalyst, ${ }^{13), 14)}$ white pigment, electrodes in devices including dye-sensitized solar cells, ${ }^{15)}$ and gas sensors. ${ }^{16)}$ Among the three distinctive modifications of titania: anatase, brookite, and rutile, anatase is a metastable phase that is generally formed at low temperatures, has been known to possess a high photocatalytic activity. The characteristics of inorganic materials can be modified by doping various components, and their performances are influenced by synthesis method, preparation condition, etc. To investigate the possibility of the formation of solid solutions in inorganic materials is interesting from the scientific and technological point of view. Many works on the synthesis and characteristics of titania solid solutions doped with a lot of transition metal cations have been reported since those having similar ionic radiuses as of $\mathrm{Ti}^{4+}$ are in some degree soluble to $\mathrm{TiO}_{2}{ }^{17), 18)}$ To prepare homogeneous anatase-type solid solutions with refractory component by the solid-state reaction is not so easy, because the metastable pure anatase phase transforms to rutile by heating in air above $635^{\circ} \mathrm{C}^{19), 20)}$ or even by mechanical grinding in general. The mild hydrothermal method using aqueous $\mathrm{TiOSO}_{4}$ solution has been applied for the formation of anatase-type solid solution nanoparticles doped with iron ${ }^{21)}$ and zirconium, ${ }^{22}$ although a variety of preparation techniques have been investigated for pure titania powders: hydrothermal treatment of $\mathrm{TiCl}_{4}$ acidic solu-

Corresponding author: M. Hirano; E-mail: hirano@aitech.ac.jp tion, ${ }^{23)}$ hydrolysis of titanium(IV) sulfate solution, ${ }^{24), 25)}$ hydrothermal oxidation of metallic titanium powder, ${ }^{26)}$ etc. Since the ionic radius and electronegativity of some metal elements are close to that of titanium(IV), anatase-type titania solid solutions doped with aluminum(III), ${ }^{27)}$ gallium(III), ${ }^{27)}$ scandium(III), ${ }^{28)}$ and niobium(V), ${ }^{29)-31)}$ and those having compositions $\mathrm{M}_{X} \mathrm{Ti}_{1-2 X} \mathrm{Nb}_{X} \mathrm{O}_{2}$ (M: trivalent cations) co-doped with these cations ${ }^{32)-35)}$ have been prepared. The ionic radius of rare-earth elements except for scandium is a little larger than that of titanium(IV). Titania added with rare-earth elements, yttrium, ${ }^{36}$ ) lanthanum, ${ }^{37)}$ cerium, ${ }^{38)}$ etc. has been tried to prepare. It has been reported that anatase nanoparticles $\mathrm{Sc}_{X} \mathrm{Ti}_{1-2 X} \mathrm{Nb}_{X} \mathrm{O}_{2}$ with wide solid solution range $(X=0-0.33)$ and anatas-type $\mathrm{ScTiNbO}_{6}$ can be hydrothermally formed by substitutional co-doping of niobium and scandium. ${ }^{34)}$ However there have been few reports on the synthesis of anatase-type titania co-doped with niobium and yttrium. From the technological standpoint, retaining the materials properties of nanoscale catalysts that operate at high temperatures is important.

In this study, titania nanoparticles co-doped with niobium and yttrium were formed from precursor solutions of $\mathrm{TiOSO}_{4}, \mathrm{NbCl}_{5}$, and $\mathrm{YCl}_{3}$ under mild hydrothermal conditions using the hydrolysis of urea. The effects of both the amount of dopant materials and the difference in the nature between yttrium and scandium as rare-earth co-dopant on the structure and properties of titania with the composition of $\mathrm{R}_{X} \mathrm{Ti}_{1-2 X} \mathrm{Nb}_{X} \mathrm{O}_{2}$ (R: rare-earth element) were investigated and discussed.

\section{Experimental}

\subsection{Sample preparation}

A mixture of an aqueous solution of reagent-grade $\mathrm{YCl}_{3}$, $\mathrm{TiOSO}_{4}$, and ethanol solution of $\mathrm{NbCl}_{5}$ in different ratios of $\mathrm{Y} / \mathrm{Ti} / \mathrm{Nb}$ was prepared in a $100 \mathrm{~cm}^{3}$ Teflon container. The solution mixture added with aqueous solution of urea was controlled to have a weakly basic condition after hydrothermal treatment by the hydrolysis of urea. The suitable amount of the urea solution was decided as the same amount of $\mathrm{H}^{+}$ion 
concentration produced by hydrolysis of starting metal salts $\mathrm{YCl}_{3}, \mathrm{TiOSO}_{4}$, and $\mathrm{NbCl}_{5}$. This solution mixture $\left(90 \mathrm{~cm}^{3}\right)$ in different ratios of $\mathrm{Y} / \mathrm{Ti} / \mathrm{Nb}$ with total cation concentrations $(\mathrm{Y}+\mathrm{Ti}+\mathrm{Nb})$ of $0.5 \mathrm{~mol} / \mathrm{dm}^{3}$ added with suitable amount of the urea solution in the Teflon container was then placed in a stainless-steel vessel. After the vessel was tightly sealed, it was heated at $100-240^{\circ} \mathrm{C}$ for $5 \mathrm{~h}$ under rotation at $1.5 \mathrm{rpm}$. After hydrothermal treatment, the precipitates were washed with distilled water until the $\mathrm{pH}$ value of the rinsed water became 7.0 , separated from the solution by centrifugation, and dried in an oven at $60^{\circ} \mathrm{C}$. The powders thus prepared were heated in an alumina crucible at heating rate $200^{\circ} \mathrm{C} / \mathrm{h}$, held at $800-1200^{\circ} \mathrm{C}$ for $1 \mathrm{~h}$ in air, and then cooled to room temperature in a furnace.

\subsection{Characterization}

The phases of the as-prepared and heat-treated powders were examined by X-ray diffractometry (XRD; model RINT-2000, Rigaku, Tokyo, Japan) using $\mathrm{Cu} \mathrm{K} \alpha$ radiation. The morphology of the as-prepared samples was observed by transmission electron microscopy (TEM; model JEM-2010, JEOL, Tokyo, Japan). The crystallite size of anatase was estimated from the line broadening of 101 diffraction peaks, according to the Scherrer equation, $D_{\mathrm{XRD}}=K \lambda / \beta \cos \theta$, where $\theta$ is the Bragg angle of diffraction lines; $K$ is a shape factor $(K=0.9$ in this work); $\lambda$ is the wavelength of incident X-rays, and $\beta$ is the corrected halfwidth given by $\beta^{2}=\beta_{\mathrm{m}}{ }^{2}-\beta_{\mathrm{s}}{ }^{2}$, where $\beta_{\mathrm{m}}$ is the measured halfwidth and $\beta_{\mathrm{s}}$ is the half-width of a standard sample. The lattice parameters were measured using silicon as the internal standard. The amounts of rutile phase formed in the heated samples were calculated from the equation: ${ }^{39)}$

$$
F_{\mathrm{R}}=\left\{1 / 1+0.79\left[I_{\mathrm{A}}(101) / I_{\mathrm{R}}(110)\right]\right\}
$$

where $F_{\mathrm{R}}$ is the mass fraction of rutile in the samples, and $I_{\mathrm{A}}(101)$ and $I_{\mathrm{R}}(110)$ the integrated 101 intensities of anatase and 110 of rutile, respectively, these lines were at $\sim 26^{\circ}$ in $2 \theta$. The specific surface area of the prepared samples was calculated from the adsorption isotherm of nitrogen at $77 \mathrm{~K}$ based on the BrunauerEmmett-Teller method (BET, model; NOVA 1200, Yuasa Ionics, Osaka, Japan). The diffuse reflectance spectra measurements for powder samples have been made. The optical absorption of these prepared powders was measured using an ultraviolet-visible spectrophotometer (V-560, Nihon Bunko, Tokyo, Japan).

The photocatalytic activity and adsorptivity of these prepared powders were separately estimated from the change in the concentration of methylene blue (guaranteed reagent grade, $\mathrm{C}_{16} \mathrm{H}_{18} \mathrm{~N}_{3} \mathrm{~S}, \mathrm{MB}$ ) both under ultraviolet ray (UV) irradiation from black light $(20 \mathrm{~W})$, and in the dark, respectively. To $200 \mathrm{~cm}^{3}$ of aqueous $\mathrm{MB}$ solution $\left(5.0 \times 10^{-5} \mathrm{~mol} / \mathrm{dm}^{3}\right), 0.10 \mathrm{~g}$ of sample powders were dispersed via ultrasonic stirring for $5 \mathrm{~min}$ and maintained in the dark for $0-5 \mathrm{~h}$ with stirring in order to estimate time dependence of adsorption of MB. On the other hand, the sample in the solution was maintained for $0-5 \mathrm{~h}$ under irradiation of ultraviolet ray with an intensity of $1 \mathrm{~mW} / \mathrm{cm}^{2}$ under stirring. Thus, the UV-light irradiation time dependence of MB concentration decomposed by the sample powders was estimated by the measurement of the concentration of $\mathrm{MB}$ remained in the solution based on the absorbance change using the spectrophotometer in comparison with the case maintained in the dark.

\section{Results and discussion}

\subsection{Preparation of anatase-type precipitates}

The influence of the hydrothermal treatment temperature on the precipitation of anatase-type titania was investigated. XRD

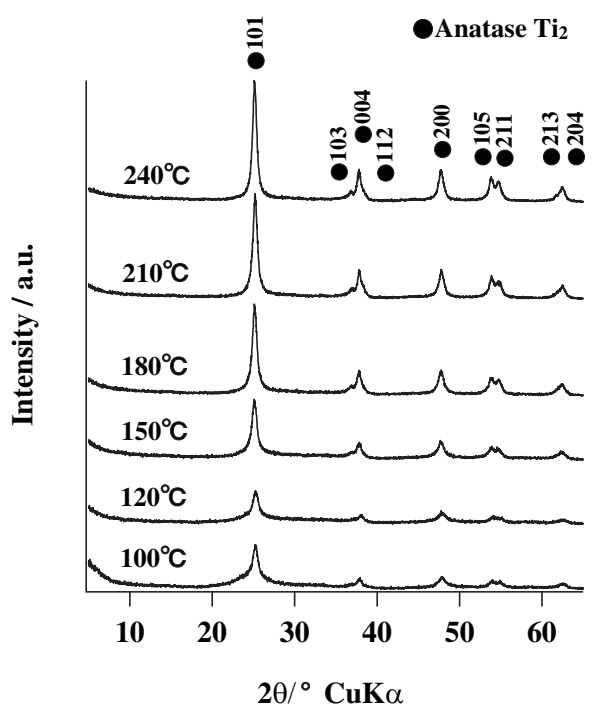

Fig. 1. X-ray diffraction patterns of precipitates prepared from precursor solutions at the starting composition of $X=0.10$ in $\mathrm{Y}_{X} \mathrm{Ti}_{1-2 X^{-}}$ $\mathrm{Nb}_{X} \mathrm{O}_{2}$ under hydrothermal conditions at various temperatures for $5 \mathrm{~h}$.

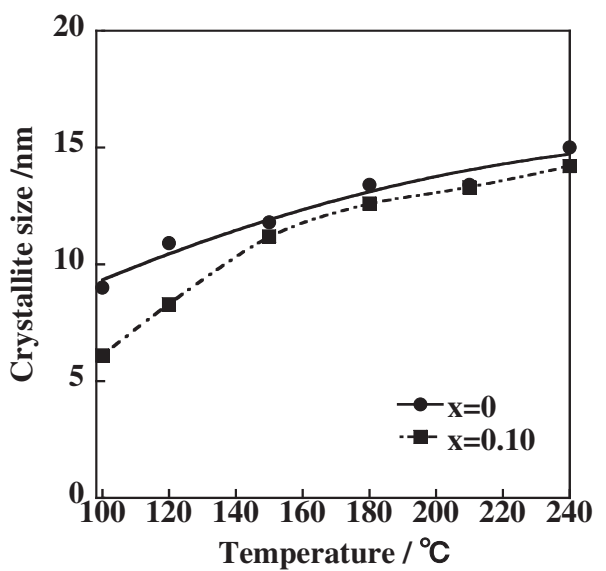

Fig. 2. Crystallite size of anatase-type precipitates prepared from precursor solutions at the starting composition of $X=0$ and 0.10 in $\mathrm{Y}_{X} \mathrm{Ti}_{1-2 X} \mathrm{Nb}_{X} \mathrm{O}_{2}$ under hydrothermal conditions plotted against hydrothermal treatment temperature.

patterns of the precipitates formed from the precursor solutions at the composition of $\mathrm{Y}_{0.10} \mathrm{Ti}_{0.80} \mathrm{Nb}_{0.10} \mathrm{O}_{2}$ under hydrothermal conditions at various temperatures for $5 \mathrm{~h}$ in the presence of urea are shown in Fig. 1. Some of XRD lines of anatase can be detected in the samples after hydrothermal treatment at 100$120^{\circ} \mathrm{C}$ for $5 \mathrm{~h}$. The precipitates were all detected as single-phase anatase, and no diffraction peaks due to other crystalline phases were detected. The XRD lines of anatase gradually became sharp with increased hydrothermal temperature.

The crystallite sizes of anatase in the samples that were formed at the composition of $X=0$ and 0.10 in $\mathrm{Y}_{X} \mathrm{Ti}_{1-2 X} \mathrm{Nb}_{X} \mathrm{O}_{2}$, estimated from the XRD line broadening are shown in Fig. 2. The crystallite sizes of the samples (pure $\mathrm{TiO}_{2}$ and $\mathrm{Y}_{0.10} \mathrm{Ti}_{0.80^{-}}$ $\mathrm{Nb}_{0.10} \mathrm{O}_{2}$ ) gradually increased when the hydrothermal treatment temperature was increased. The crystallite sizes of anatase prepared at the composition of $X=0.10$ are slightly smaller than those prepared at the composition of $X=0$, pure $\mathrm{TiO}_{2}$. 


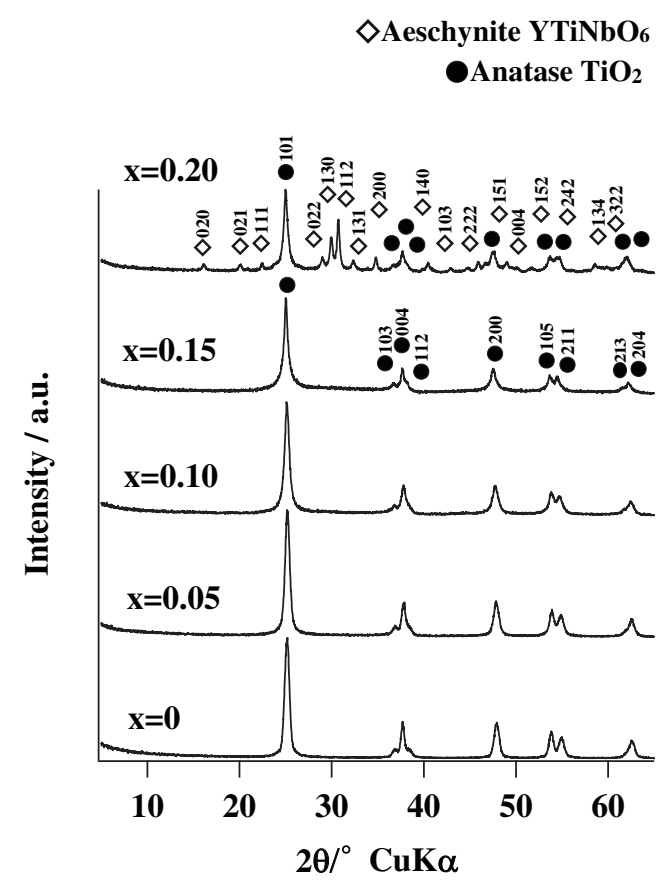

Fig. 3. X-ray diffraction patterns of precipitates prepared from precursor solutions at various compositions of $X=0-0.20$ in $\mathrm{Y}_{X} \mathrm{Ti}_{1-2 X^{-}}$ $\mathrm{Nb}_{X} \mathrm{O}_{2}$ under hydrothermal conditions at $240^{\circ} \mathrm{C}$ for $5 \mathrm{~h}$.

Figure 3 shows XRD patterns of as-prepared samples that were precipitated at the compositions of $X=0$ to 0.20 in $\mathrm{Y}_{X} \mathrm{Ti}_{1-2 X} \mathrm{Nb}_{X} \mathrm{O}_{2}$ under hydrothermal conditions at $240^{\circ} \mathrm{C}$. The precipitates that were formed at the compositions up to $X=0.15$ were all detected as single-phase anatase-type structure, and no diffraction peaks due to other crystalline phases were detected. The XRD pattern of the precipitate formed at the composition of $X=0.20$ shows the appearance of aeschynite phase $\mathrm{YTiNbO}_{6}$ coexisting with anatase-type titania. Since the ionic radius of yttrium is a little larger than that of scandium, the aeschynite phase in addition to the anatase phase is considered to appear in the case of $\mathrm{Y}_{X} \mathrm{Ti}_{1-2 X} \mathrm{Nb}_{X} \mathrm{O}_{2}$ at the composition of $X>0.15$, though anatase phase can exist as solid solutions with wide solid solution range $(X=0-0.33)$ in the case of $\left.\mathrm{Sc}_{X} \mathrm{Ti}_{1-2 X} \mathrm{Nb}_{X} \mathrm{O}_{2} \cdot{ }^{34}\right)$

The TEM images of the precipitates formed at the compositions of $X=0$ to 0.15 in $\mathrm{Y}_{X} \mathrm{Ti}_{1-2 X} \mathrm{Nb}_{X} \mathrm{O}_{2}$ under hydrothermal conditions at $240^{\circ} \mathrm{C}$ are shown in Fig. 4. The particle sizes of the samples with the composition of $X=0.05$ and 0.10 are observed to be around $15-25 \mathrm{~nm}$ and they are a little larger than that of pure $\mathrm{TiO}_{2}, X=0$. The effect of the co-existence of small amount of niobium and yttrium on the increase in particle size i.e., agglomeration of nanoparticles is observed in the samples prepared at the compositions $X=0.05$ and 0.10 , though the crystallite sizes of anatase were approximately $15 \mathrm{~nm}$ in these samples. On the other hand, the existence of fine particles below $10 \mathrm{~nm}$ was observed in the sample $X=0.15$. It is considered that the sample $X=0.15$ is not homogeneous and consists of mixtures of anatase with crystallite having $15 \mathrm{~nm}$ and smaller particles $(<10 \mathrm{~nm})$ with low crystallinity. The specific surface areas of the as-prepared anatase powders is shown in Fig. 5. The specific surface areas of the samples gradually increase when the niobium and yttrium content is increased, which may be due to the presence and the amount of fine particles with low crystallinity. The behavior in the specific surface area of the samples had relation to the change in the particle sizes observed in TEM images (Fig. 4).

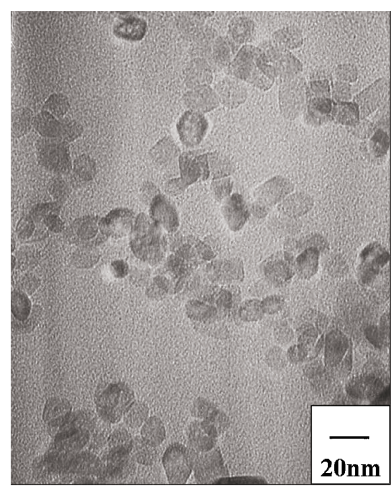

(a)

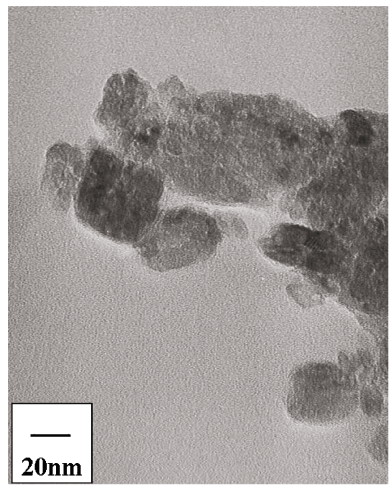

(c)

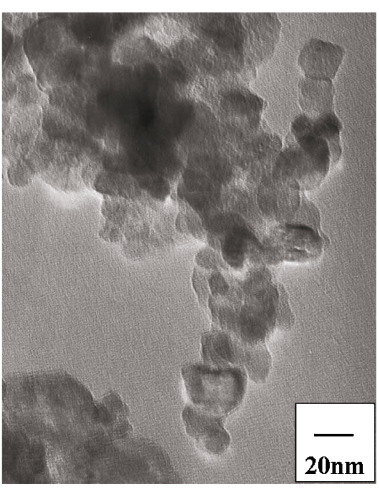

(b)

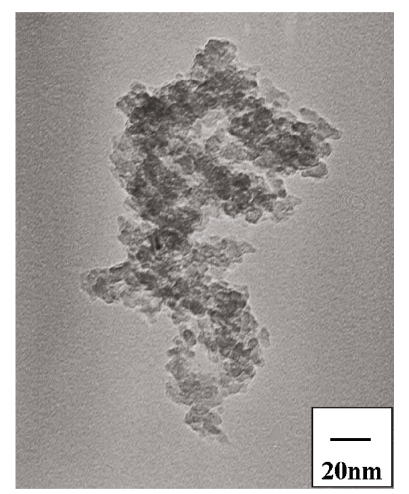

(d)
Fig. 4. Transmission electron microscopy images of precipitates prepared from precursor solutions at various compositions of (a) $X=0$, (b) $X=0.05$, (c) $X=0.10$, and (d) $X=0.15$ in $\mathrm{Y}_{X} \mathrm{Ti}_{1-2 X} \mathrm{Nb}_{X} \mathrm{O}_{2}$ under hydrothermal conditions at $240^{\circ} \mathrm{C}$ for $5 \mathrm{~h}$.

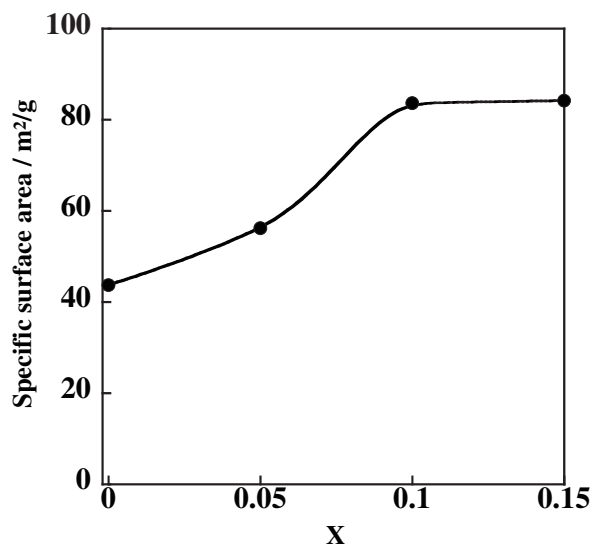

Fig. 5. BET specific surface areas of the samples formed from precursor solutions at the compositions of $\mathrm{Y}_{X} \mathrm{Ti}_{1-2 X} \mathrm{Nb}_{X} \mathrm{O}_{2}, X=0-0.15$ at $240^{\circ} \mathrm{C}$ for $5 \mathrm{~h}$

The relationship between the lattice constants of as-prepared anatase and composition is shown in Fig. 6. With increasing dopant content $X$, the lattice parameters $a_{0}$ and $c_{0}$ clearly show a linear increase. The change in the lattice parameters with composition is one of the evidences for the formation of anatasetype solid solutions $\left(\mathrm{Y}_{X} \mathrm{Ti}_{1-2 X} \mathrm{Nb}_{X} \mathrm{O}_{2}, X=0-0.15\right)$ under hydrothermal conditions at $240^{\circ} \mathrm{C}$. 


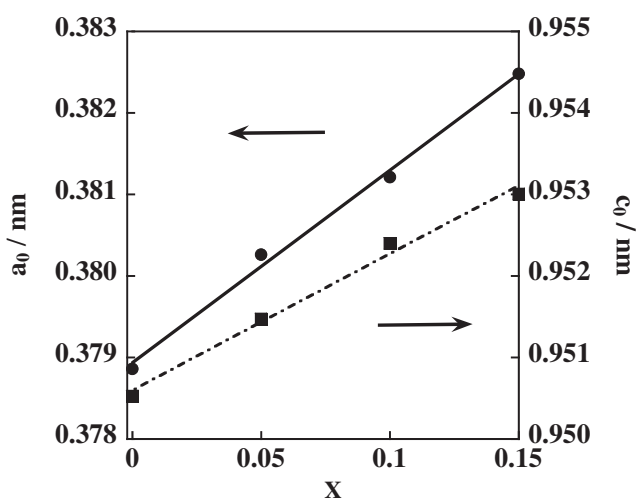

Fig. 6. Lattice parameters of anatase of the samples formed from precursor solutions at the compositions of $\mathrm{Y}_{X} \mathrm{Ti}_{1-2 X} \mathrm{Nb}_{X} \mathrm{O}_{2}$ at $240^{\circ} \mathrm{C}$ for $5 \mathrm{~h}$.

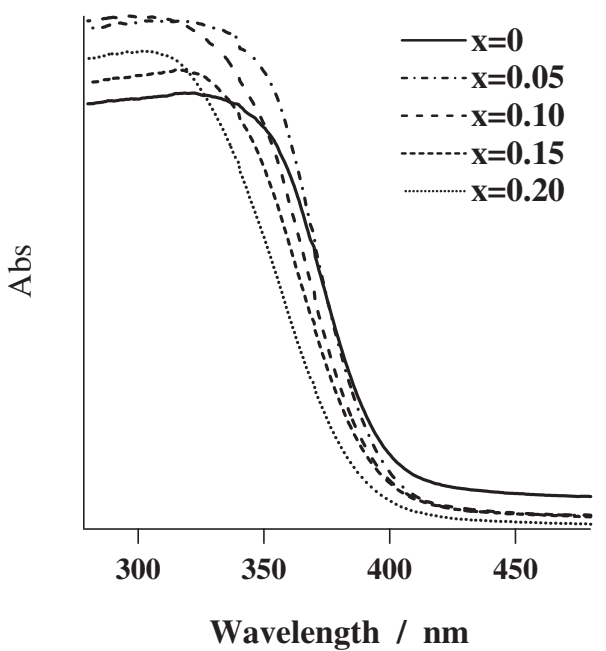

Fig. 7. Diffuse reflectance spectrum of the samples formed at the compositions of $\mathrm{Y}_{X} \mathrm{Ti}_{1-2 X} \mathrm{Nb}_{X} \mathrm{O}_{2}, X=0-0.15$.

\subsection{Characteristics of anatase-type precipitates}

The diffuse reflectance spectra of the as-prepared samples formed at the composition of $\mathrm{Y}_{X} \mathrm{Ti}_{1-2 X} \mathrm{Nb}_{X} \mathrm{O}_{2}$ are shown in Fig. 7. By substitutional doping of niobium and yttrium, onset of absorption slightly shifted to shorter wavelengths. The optical band gap is obtained, using $\alpha h \nu=$ const $\left(h \nu-E_{\mathrm{g}}\right)^{\mathrm{n}}$, where $\alpha$ is the absorption coefficient, $n=1 / 2$ for a direct allowed transition, and $n=2$ for an indirect allowed transition. Figure 8 shows the optical band-gap values for the samples, which were determined from the energy intercept by extrapolating the straight regions of the plot of $(\alpha h \nu)^{2}$ versus the photon energy $h v$ for a direct allowed transition $\left(E_{\mathrm{d}}\right)$. The optical band-gap value of samples slightly and gradually increased with the increase in the content of niobium and yttrium in the samples.

The phase stability of the as-prepared anatase-type $\mathrm{Y}_{X} \mathrm{Ti}_{1-2 X^{-}}$ $\mathrm{Nb}_{X} \mathrm{O}_{2}$ in the course of heating in air was investigated. The XRD patterns of the as-prepared samples with the composition of $\mathrm{Y}_{0.05} \mathrm{Ti}_{0.90} \mathrm{Nb}_{0.05} \mathrm{O}_{2}$ as-prepared and after being heated at various temperatures are shown in Fig. 9. The result of the kinetic study on the anatase-to-rutile phase transformation showed that the anatase-type pure $\mathrm{TiO}_{2}$ changes to rutile-type structure by heat treatment above $635^{\circ} \mathrm{C} .{ }^{19), 20)}$ Although a small amount of euxenite-type $\mathrm{YTiNbO}_{6}$ phase is detected in the sample after heating above $850^{\circ} \mathrm{C}$, titania existed as almost anatase-phase. It is

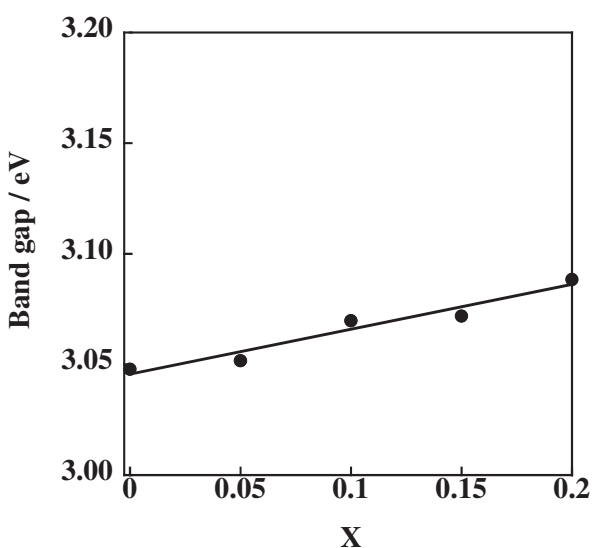

Fig. 8. Optical band gap of the samples formed at the compositions of $\mathrm{Y}_{X} \mathrm{Ti}_{1-2 X} \mathrm{Nb}_{X} \mathrm{O}_{2}, X=0-0.20$.

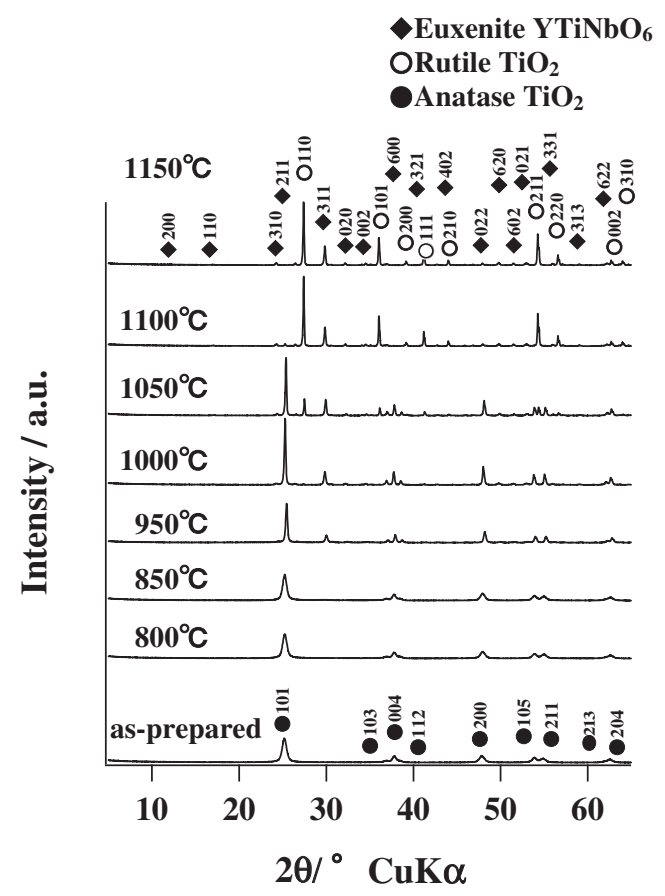

Fig. 9. X-ray diffraction patterns of the samples formed at the composition of $\mathrm{Y}_{0.05} \mathrm{Ti}_{0.90} \mathrm{Nb}_{0.05} \mathrm{O}_{2}$ and after being heated at various temperatures for $1 \mathrm{~h}$.

considered that the precipitation of the euxenite-type $\mathrm{YTiNbO}_{6}$ out of the metastable anatase-type titania is due to the decrease in the solubility of niobium and yttrium into anatase-type titania with increased crystallinity that has grown into large particles via heating at high temperature above $900^{\circ} \mathrm{C}$. Although it is observed that the precipitation behavior of $\mathrm{TiNb}_{2} \mathrm{O}_{7}$ out of the niobiumdoped anatase followed by continual and clear decrease in the lattice parameters of metastable anatase in the case of niobiumdoped anatase-type $\mathrm{TiO}_{2},{ }^{31)}$ this precipitation phenomenon in the course of heating did not occurred in the case of other co-dopants such as scandium, aluminum, and gallium in the composition range of $X=0-0.15$ in $\mathrm{M}_{X} \mathrm{Ti}_{1-2 X} \mathrm{Nb}_{X} \mathrm{O}_{2}(\mathrm{M}=\mathrm{Sc}, \mathrm{Al}$, and $\mathrm{Ga})^{32)-35)}$ The sample maintained almost anatase structure even after heating at $1000^{\circ} \mathrm{C}$ for $1 \mathrm{~h}$. The anatase-to-rutile phase transformation started at the temperature above $1000^{\circ} \mathrm{C}$ and concluded at $1150^{\circ} \mathrm{C}$. 


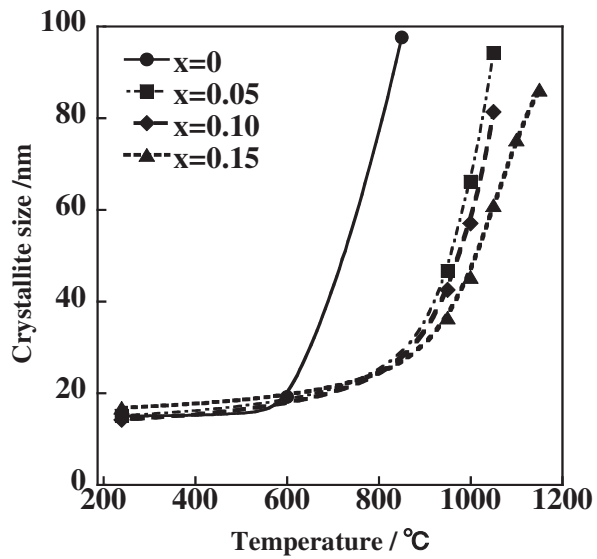

Fig. 10. Crystallite size of anatase in the samples formed at the compositions of $\mathrm{Y}_{X} \mathrm{Ti}_{1-2 X} \mathrm{Nb}_{X} \mathrm{O}_{2}, X=0-0.15$ plotted against heating temperature.

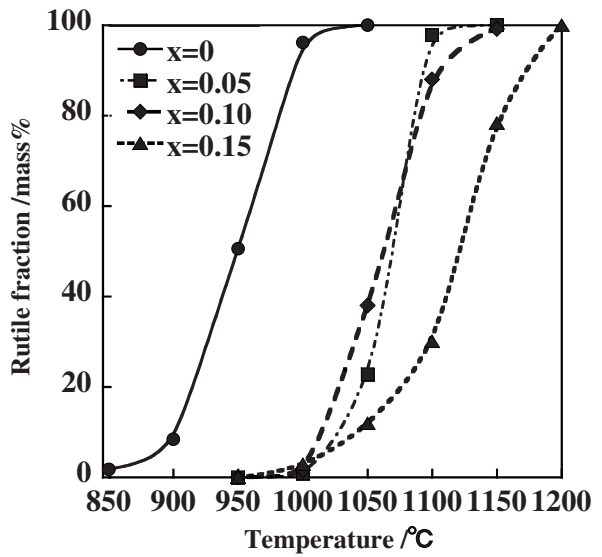

Fig. 11. Phase transformation from anatase-type to rutile-type structure for the samples formed at the compositions of $\mathrm{Y}_{X} \mathrm{Ti}_{1-2 X} \mathrm{Nb}_{X} \mathrm{O}_{2}, X=0$ 0.15 plotted against heating temperature.

The crystallite growth of anatase in the samples is shown as a function of heating temperature in Fig. 10. The heating temperature necessary to grow up to be more than $90 \mathrm{~nm}$ for the crystallite of anatase in the samples $X=0,0.05$, and 0.15 was approximately 850,1050 , and $1150^{\circ} \mathrm{C}$, respectively. The copresence of niobium and yttrium delays the crystallite growth of anatase, which is considered to closely relate to the shift of the phase transformation temperature. The proportion of the anataseto-rutile phase transformation ratios for the present samples $\left(\mathrm{Y}_{X} \mathrm{Ti}_{1-2 X} \mathrm{Nb}_{X} \mathrm{O}_{2}\right)$ is plotted as a function of heat treatment temperature in Fig. 11. The anatase-type pure $\mathrm{TiO}_{2}$ (sample $X=0$ ), which was hydrothermally formed by crystallization from $\mathrm{TiOSO}_{4}$ solution using the hydrolysis of urea, originally has higher phase stability than that obtained from titanium alkoxide. This high phase stability is thought to be due to the probable existence of residual impurity $\mathrm{SO}_{4}{ }^{2-}$ that was not removed perfectly via washing from the precipitates. By the co-presence of niobium and yttrium, the starting and completion temperature of the phase transformation were shifted from 850 to $1000^{\circ} \mathrm{C}$ and from 1000 to $1100-1200^{\circ} \mathrm{C}$, respectively. It is clear that the phase transformation was delayed and the phase stability of the anatase was enhanced by the co-presence of these elements. It has been reported that the stable rutile-type $\mathrm{M}_{X} \mathrm{Ti}_{1-2 X} \mathrm{Nb}_{X} \mathrm{O}_{2}$ solid solutions $(\mathrm{M}=\mathrm{Sc}, \mathrm{Al}$, and $\mathrm{Ga}, X=0-0.15)$ consisting of a single

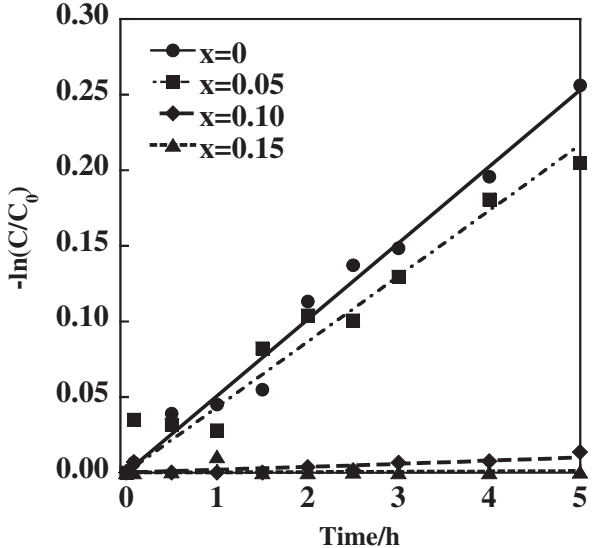

Fig. 12. Photocatalytic degradation of $\mathrm{MB}$ as a function of $\mathrm{UV}$ irradiation time for the samples formed at the compositions of $\mathrm{Y}_{X} \mathrm{Ti}_{1-2 X} \mathrm{Nb}_{X} \mathrm{O}_{2}, X=0-0.15$

phase are formed through the anatase-to-rutile phase transformation. ${ }^{32), 33), 35)}$ Although metastable anatase-type $\mathrm{Y}_{X} \mathrm{Ti}_{1-2 X^{-}}$ $\mathrm{Nb}_{X} \mathrm{O}_{2} \quad(X=0-0.15)$ were formed under the hydrothermal conditions in the present study, a single phase of rutile-type $\mathrm{Y}_{X} \mathrm{Ti}_{1-2 X} \mathrm{Nb}_{X} \mathrm{O}_{2}$ was not formed through the phase transformation in the same composition range as the cases of co-dopant $\mathrm{M}=\mathrm{Sc}, \mathrm{Al}$, and $\mathrm{Ga}$, which is due to a little larger ionic radius of yttrium than that of scandium, aluminum, and gallium.

The influence of the co-presence of yttrium and niobium on the photocatalytic activity of the as-prepared anatase samples was investigated. The photocatalytic activity i.e., photodegradation amount of MB for the as-prepared anatase samples versus UVlight irradiation time is shown in Fig. 12. The photodegradation amount of MB increased with UV-light irradiation time in the asprepared pure $\mathrm{TiO}_{2}$ and $\mathrm{Y}_{0.05} \mathrm{Ti}_{0.90} \mathrm{Nb}_{0.05} \mathrm{O}_{2}$ samples. The anatase with composition $\mathrm{Y}_{0.05} \mathrm{Ti}_{0.90} \mathrm{Nb}_{0.05} \mathrm{O}_{2}$ showed the same level of photocatalytic activity as that of pure $\mathrm{TiO}_{2}$. The decrease in the photocatalytic activity in the samples $X \geq 1.0$ is partly due to the decrease in substantial $\mathrm{TiO}_{2}$ content and decrease in the crystallinity of anatase in the samples, though it is not appropriate to mention the details of factors decreasing photocatalytic activity from only this experiment. The finding in this study i.e., shifting of the beginning of the anatase-to-rutile phase transformation to higher temperature indicates an issue of great importance for retaining the materials properties of nanoscale catalysts that operate at high temperatures, though the increase in the amount of substitution of $\mathrm{Ti}$ by $\mathrm{Y}$ and $\mathrm{Nb}$ was not effective for the improvement of photo-decomposition of MB under UV irradiation.

\section{Summary}

Anatase-type titania nanoparticles co-doped with niobium and yttrium $\left(\mathrm{Y}_{X} \mathrm{Ti}_{1-2 X} \mathrm{Nb}_{X} \mathrm{O}_{2}\right.$ in the range of $\left.X=0-0.15\right)$ were formed from precursor solutions of $\mathrm{TiOSO}_{4}, \mathrm{NbCl}_{5}$, and $\mathrm{YCl}_{3}$ under hydrothermal conditions at $240^{\circ} \mathrm{C}$ for $5 \mathrm{~h}$ using the hydrolysis of urea. The effect of dopant materials on the structure, crystallite growth, photocatalytic activity, and phase stability of anatase-type $\mathrm{TiO}_{2}$ was investigated. The lattice parameters $a_{0}$ and $c_{0}$ of anatase slightly and gradually increased with increase in niobium and yttrium content in the samples. The anatase nanoparticles doped with niobium and yttrium did not show superior photocatalytic activity. The anatase-to-rutile phase transformation shifted to higher temperature via co-doping 
niobium and yttrium into $\mathrm{TiO}_{2}$. The appearance of $\mathrm{YTiNbO}_{6}$ phase was observed via heat-treatment before the formation of rutile through the anatase-to-rutile phase transformation. The rutile-type titania together with $\mathrm{YTiNbO}_{6}$ phase were formed after the phase transformation.

Acknowledgments The present work was partly supported by Grant-in-Aids No. 21560703 for Scientific Research from the Ministry of Education, Culture, Sports, Science, and Technology of Japan.

\section{References}

1) E. Matijević, Annu. Rev. Mater. Sci., 15, 483-516 (1985).

2) M. Yoshimura, J. Mater. Res., 13, 796-802 (1998).

3) C. N. R. Rao, S. R. C. Vivekchand, K. Biswas and A. Govindaraj, Dalton Trans., 3728-3749 (2007).

4) S.-I. Hirano, Ceram. Bull., 66, 1342-1344 (1987).

5) W. J. Dawson, Ceram. Bull., 67, 1673-1678 (1988).

6) S. H. Yu, J. Ceram. Soc. Japan, 109, S65-S75 (2001).

7) S. Komarneni, Curr. Sci., 85, 1730-1734 (2003).

8) R. K. Roeder and E. B. Slamovich, J. Am. Ceram. Soc., 82, 1665-1675 (1999).

9) M. Hirano, H. Morikawa and M. Inagaki, J. Am. Ceram. Soc., 85, 1915-1920 (2002).

10) M. Hirano, T. Miwa and M. Inagaki, J. Ceram. Soc. Japan, 109, 401-405 (2001).

11) W. J. Schuele and V. D. Deetscreek, J. Appl. Phys., 32, 235S236S (1961).

12) M. Hirano, J. Mater. Chem., 10, 469-472 (2000).

13) M. A. Fox and M. T. Dulay, Chem. Rev., 93, 341-357 (1993).

14) O. Carp, C. L. Huisman and A. Reller, Prog. Solid State Chem., 32, 33-177 (2004).

15) U. Bach, D. Lupo, P. Comte, J. E. Moser, F. Weissortel, J. Salbeck, H. Spreitzer and M. Graetzel, Nature, 395, 583-585 (1998).

16) J.-Y. Park, S.-J. Song and E. D. Wachsman, J. Am. Ceram. Soc., 93, 1062-1068 (2010).

17) K. J. D. Mackenzie, Trans. J. Br. Ceram. Soc., 74, 77-84 (1975).
18) C. N. R. Rao, A. Turner and J. M. Honig, J. Phys. Chem., 11, 173-175 (1959).

19) A. W. Zzanderna, C. N. R. Rao and J. M. Honig, Trans. Faraday Soc., 54, 1069-1073 (1958).

20) S. R. Yoganarasimhan and C. N. R. Rao, Trans. Faraday Soc., 58, 1579-1589 (1962).

21) M. Hirano, T. Joji, M. Inagaki and H. Iwata, J. Am. Ceram. Soc., 87, 35-41 (2004).

22) M. Hirano, C. Nakahara, K. Ota, O. Tanaike and M. Inagaki, J. Solid State Chem., 170, 39-47 (2003).

23) D. N. Furlong and G. D. Parfitt, J. Colloid Interface Sci., 65, 548-554 (1978).

24) J. F. Duncan and R. G. Richards, N. Z. J. Sci., 19, 179-183 (1976).

25) J. F. Duncan and R. G. Richards, N. Z. J. Sci., 19, 185-194 (1976).

26) Y. Qian, Q. Chen, Z. Chen, C. Fan and G. Zhou, J. Mater. Chem., 3, 203-205 (1993).

27) L. E. Depero, A. Marino, B. Allieri and E. Bontempi, J. Mater. Res., 15, 2080-2086 (2000).

28) M. Hirano and K. Date, J. Am. Ceram. Soc., 88, 2604-2607 (2005).

29) M. Hirano and K. Matsushima, J. Nanosci. Nanotechnol., 6, 762-770 (2006).

30) M. Hirano and K. Matsushima, J. Am. Ceram. Soc., 89, 110117 (2006).

31) M. Hirano and Y. Ichihashi, J. Mater. Sci., 44, 6135-6143 (2009).

32) M. Hirano and T. Ito, J. Nanosci. Nanotechnol., 6, 3820-3827 (2006).

33) M. Hirano and T. Ito, Mater. Res. Bull., 43, 2196-2206 (2008).

34) M. Hirano and T. Ito, J. Solid State Chem., 182, 1581-1586 (2009).

35) M. Hirano and T. Ito, J. Ceram. Soc. Japan, 118, 1170-1175 (2010).

36) Y. T. Wong, N. B. Wong and L. Shi, J. Mater. Sci., 38, 973-977 (2003).

37) C. P. Sibu, S. R. Kumar, P. Mukundan and K. G. K. Warrier, Chem. Mater., 14, 2876-2881 (2002).

38) Y. Xie and C. Yuan, Appl. Catal., B, 46, 251-259 (2003).

39) R. A. Spurr and H. Myers, Anal. Chem., 29, 760-763 (1957). 